\title{
Marguerite de Valois, Album de poésies
}

\section{Michele Mastroianni}

\section{(2) OpenEdition}

\section{Journals}

\section{Edizione digitale}

URL: http://journals.openedition.org/studifrancesi/6250

DOI: 10.4000/studifrancesi.6250

ISSN: 2421-5856

\section{Editore}

Rosenberg \& Sellier

\section{Edizione cartacea}

Data di pubblicazione: 1 novembre 2010

Paginazione: 543

ISSN: 0039-2944

\section{Notizia bibliografica digitale}

Michele Mastroianni, «Marguerite de Valois, Album de poésies», Studi Francesi [Online], 162 (LIV | III) |

2010, online dal 30 novembre 2015, consultato il 11 janvier 2021. URL: http://

journals.openedition.org/studifrancesi/6250 ; DOI: https://doi.org/10.4000/studifrancesi.6250

\section{Questo documento è stato generato automaticamente il 11 janvier 2021.}

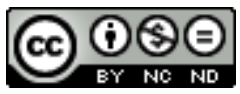

Studi Francesi è distribuita con Licenza Creative Commons Attribuzione - Non commerciale - Non opere derivate 4.0 Internazionale. 


\title{
Marguerite de Valois, Album de poésies
}

\author{
Michele Mastroianni
}

\section{NOTIZIA}

MARGUERITE DE VALOIS, Album de poésies, édition de Colette winN et François ROUGET, Éditions Classiques Garnier, 2009 («textes de la Renaissance», 158), pp. 615.

1 L'album de poésies diventa, negli anni 1570-80, una moda nei salons della grande aristocrazia francese, ove rappresenta un omaggio alla nobile ospite. Su iniziativa di un frequentatore o su richiesta della padrona di casa, desiderosa di affermare il suo ruolo intellettuale e di lasciare un ricordo della sua azione di promotrice culturale, si diffonde l'uso di riunire in raccolte collettive le composizioni poetiche prodotte nell'ambito delle riunioni mondane organizzate dalla dedicataria o ricollegabili ai rapporti personali con quest'ultima o con il suo entourage. Parecchi di questi albums ci sono giunti: recente è l'edizione critica dell'Abum de poésies della marechale de Retz (a cura di C.H. Winn e F. Roget, Paris, Champion, 2004). Viene ora pubblicato per la prima volta nella sua integralità l'album di versi dedicato a Marguerite de Valois, regina di Navarra, moglie del futuro Enrico IV. L'album fu composto tra il 1578 e il 1584, durante due soggiorni di Marguerite a Nérac in Guascogna, ove essa teneva corte brillante, anche se alcuni pezzi ivi trascritti risalgono al periodo intorno al 1570. Esso comprende 218 composizioni copiate da mani diverse a differenti intervalli. Quando la raccolta era già completata, una nuova mano ha aggiunto alcune volte l'attribuzione a un autore. Non è possibile ricercare un ordine o pretendere un'unità specifica, cronologica o tematica, delle poesie qui riunite: sembra tuttavia che l'organizzatore o gli organizzatori del corpus abbiano cercato, nei limiti del possibile, di raggruppare le composizioni di uno stesso autore. Malgrado le sporadiche attribuzioni di cui si è detto, l'anonimato è la regola dell'album. Alcuni autori erano già stati identificati dagli studiosi, qualche identificazione è stata aggiunta dai curatori della presente edizione. Fra i testi riconosciuti abbiamo poesie di Ronsard, Jamyn, Desportes, Constans, la 
traduzione della seconda delle Heroides di Ovidio fatta da Madeleine de l'Aubespine e ben 80 composizioni di Agrippa d'Aubigné (alcune rimaste fino ad oggi inedite). Come hanno sottolineato i curatori, «numerosi sono gli indizi che permettono di considerare l'album di Marguerite come l'espressione di un'estetica di salon il cui principio motore è il dialogo poetico. Più che la dominante amorosa, la preferenza per certe forme (stanze e sonetti), o ancora la scelta esclusiva del francese, è la natura della comunicazione che singolarizza il discorso, una comunicazione segnata dallo scambio reciproco e dalla diffusione verso un punto centrale occupato dalla regina, soggetto principale delle composizioni o destinataria privilegiata delle poesie che essa accoglie» (p. 47). L'album è una testimonianza di prim'ordine per la ricostruzione di un contesto letterario e apporta materiale utile per gli studiosi della genetica testuale. 